\title{
Tuberculosis control in Ecuador: Unforeseen problems, unanticipated strengths
}

\author{
Stan Houston MD FRCPC \\ University of Alberta, Edmonton \\ Technical Consultant to the Canadian Lung Association Canada/Ecuador Project
}

E cuador is among the eight countries with the highest tuberculosis (TB) prevalences in the Americas (the World Health Organization estimates 141 new cases/100,000 population in 2002) and has had a poorly functioning TB control program. As described in an earlier editorial (1), the Canadian Lung Association, with funding from the Canadian International Development Agency, has been involved for four years in supporting Ecuador's National TB Program. The initial phase of the project has just been completed, but the experience has already provided many valuable lessons, some quite unexpected.

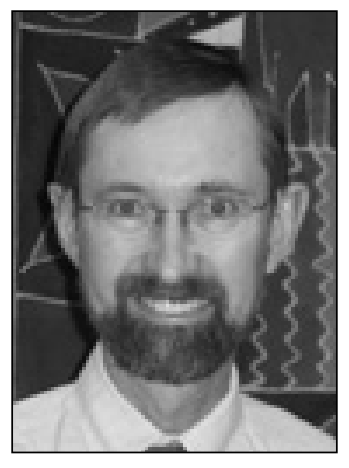

Stan Houston

that DOTS was not a backward step for Ecuadorian patients and physicians!

Another ongoing challenge, not really addressed in low and middle income countries until very recently, is that of multidrug-resistant $\mathrm{TB}$. The situation in Ecuador is complicated by continued pressure from clinicians for the rapid implementation of a complex and costly program to treat these patients. The project has struggled to balance the urgency and immense potential benefits of implementing DOTS (including the fact that good DOTS is the primary means of preventing drug resistance) with the concerns of local physicians and the needs of those patients who already have multidrugresistant $\mathrm{TB}$.

\section{THE CONTEXT: ECONOMIC AND BUREAUCRATIC CHALLENGES}

During the four years of the project, the position of Head of the National TB Program has changed seven times. A former Minister of Health absconded with millions of dollars in public funds. One government was brought down by popular protest, and the country adopted the American dollar in an effort to deal with chronic financial crises that have made Ecuador one of the world's most highly indebted nations. The country ranked 114th of 133 countries in Transparency International's most recent Corruption Perception Index (where 1 is least corrupt) (2). Throughout the project, labour unrest in the health sector has been almost the rule, rather than the exception. These and other factors create a challenging environment for the implementation of a program such as TB control, which requires long term stability and consistency.

Our learning curve in dealing with bureaucracies was by no means limited to Ecuador. During the short life of the project, Canadian International Development Agency's global geographical focus has shifted away from Latin America. We are actively exploring potential funding sources, including the Global Fund for AIDS, Tuberculosis and Malaria, as well as the United States Agency for International Development.

\section{THE TRADITIONAL MODEL}

The International Union Against Tuberculosis and Lung Disease (IUATLD) model for mutual assistance programs was developed in Africa to serve poor, rural communities with limited health infrastructure and few specialist physicians. In spite of Ecuador's current economic difficulties, the country has eight medical schools for 13.5 million people, a substantial cadre of subspecialist pulmonologists and a number of referral hospitals. It quickly became apparent that one of the challenges facing Directly Observed Therapy Short Course (DOTS) implementation was persuading the medical community

\section{STRENGTHS}

When it became apparent that the standard IUATLD model was not a good fit in Ecuador, we decided to try something different. We concluded that it was essential to have a team on the ground in Ecuador, even though this was a major deviation from the standard IUATLD/World Health Organization approach. Under the guidance of program manager Lucero Hernandez, a Colombian Canadian with infinite patience and deep insight into the workings of Latin America, a small project team of Ecuadorian doctors and nurses was assembled. Their commitment, abilities and local knowledge proved to be the project's greatest strength. The primary role of the Ecuadorian project team was to work with the Ministry of Health providing intensive DOTS training to the staff of peripheral health units. Using their experience and input, the project's strategy was further refined. One critical early development was the team's recognition of the need for follow-up and reinforcement training in the field ('capacitación en servicio') immediately after each initial training workshop.

A particularly gratifying and exciting observation during field visits has been the response of health workers at the primary care level - the backbone of the TB program. They not only demonstrate great commitment and enthusiasm in delivering DOTS, but also remarkable initiative in identifying the unique problems and barriers to DOTS implementation in their areas, as well as in developing locally appropriate solutions. Local staff tell us that they like the quality of the training and support, the reward of seeing their patients get better and the satisfaction of participating in a program that works, as documented by their own results. The development of capacity and support for DOTS at grassroots levels in the health system is an important element in making the program sustainable. 


\section{SUSTAINABILITY}

Throughout the project, the Ecuadorian government has assumed responsibility for the major recurrent costs of the TB program drugs, staff and infrastructure, while the Canadian funds have gone largely to a front end-loaded investment in training. This characteristic of the Ecuadorian model of TB program support would also be expected to contribute to sustainability.

\section{OUTCOMES}

A comprehensive report of project and National TB Program results will be presented in a separate publication. Briefly, 'true DOTS' - with every dose of treatment directly supervised - is now provided in every health unit in the public sector throughout the three pilot project provinces, which together account for $51 \%$ of the country's population and more than one-half of its estimated TB cases. Moreover, a large number of Ecuadorian health workers have had the opportunity to see that they are capable of providing TB treatment of the highest international standards.

\section{NOW WHAT?}

Plans to complete the project by extending it to the rest of the country are awaiting funding decisions. Because the pilot project came in under budget, we have been able to initiate some preliminary expansion activities using the remaining funds. The uncertainty concerning the project's future is all the more difficult to accept, knowing that provision of TB treatment to the other 18 provinces and the remaining one-half of Ecuador's population is an entirely achievable goal.

\section{REFERENCES}

1. Tannenbaum TN. Sustainable tuberculosis control. Can Respir J 2002;9:387-8.

2. Transparency International. Corruption Perceptions Index 2003. $<$ http://www.transparency.org/cpi/2003/cpi2003.en.html>

(Version current at March 26, 2004)

\section{Going the extra mile: A new life for Darwin}

$S_{\text {ix }}^{\text {ix }}$ ixteen-year-old Darwin Molina Cabascango didn't get many breaks in life. Born in Quito, Ecuador, into a poor family, he grew up in an atmosphere of alcoholism and abuse. "This led me to drugs," he says. "My friends told me that this way, one forgets about everything. This is not true. When the effect was gone, I would feel worse ... but I could not give it up."

Darwin's eight-year addiction to glue sniffing almost cost him his life. In May 2002, he began to cough and spit up phlegm. Finally, his mother brought him to the local clinic, where tests confirmed that he had tuberculosis. He began treatment immediately, but soon developed a rash. "Nobody knew that I was an addict," he recounts, "and the medication started to do me harm. The nurses ... gave me such confidence that I decided to tell them about my problem."

Concerned at the pain [that] he was causing his mother, Darwin asked for help with his addiction. After some searching, the nurses managed to find him a bed in a treatment centre at no cost to him. "At the beginning, it was really hard," he says, "but what gave me strength were the nurses in the health centre who never abandoned me."

Going the extra mile for their patients is all part of the service provided by the local health care professionals working with the Canadian International Development Agencysupported National Tuberculosis Strengthening Program in Ecuador. Implemented by the Canadian Lung Association, this program is helping Ecuador to provide front-line care for tuberculosis patients through training in diagnosis, treatment, reporting and recording, provision of equipment, improvements to the laboratory network, and public education and awareness.

In 2001, when the program began, there were an estimated 18,140 cases of tuberculosis in Ecuador. Worldwide, tuberculosis still claims more than two million deaths a year and infects about one in every three persons. The impact - a highly infectious disease that is not only fatal for many, but also drains productivity from adults and learning capacity from children is enormous on a poor country like Ecuador. Yet, for an investment of $\$ 10 /$ patient, this disease can be cured with the Directly Observed Treatment Short Course or DOTS.

Thanks to the support offered by this program, morale at the local level is high. Nurses, lab technicians and other health care workers have exceeded all of their targets and have formed their own network of practice, sharing knowledge and experience, solving common problems and reinforcing each others' successes. The Canadian Lung Association has managed their resources shrewdly, saving enough money to extend the program by another year. They are now working in three pilot provinces and benefiting more than 5.4 million people.

That includes people like Darwin and his family. The nurses go well beyond simply educating the public about tuberculosis, helping people find jobs and deal with social and personal problems like drug addiction. Mrs Ruth Gallardo, one of Darwin's nurses, is proud of his success: "In March of 2003, he was released from the Treatment Centre, recovered from his addiction," she says. "He is now doing his military service in the Ecuadorian Army, he's totally integrated into society and is rebuilding his life with great enthusiasm."

Darwin is looking beyond his own recovery to a better life for his family. "Thanks to the Health Centre, and to my mother and my brothers who were always by my side, even in my worst moments - and also, why not thank my father, who in a way also motivated me to recover - I hope that all will change and that my family will once again be mine," he says.

The above was written by the Canadian International Development Agency and can be found on their Web site. It is reproduced with the permission of the Minister of Public Works and Government Services, 2004. 


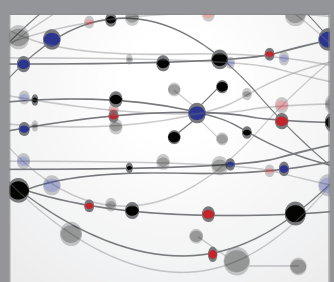

The Scientific World Journal
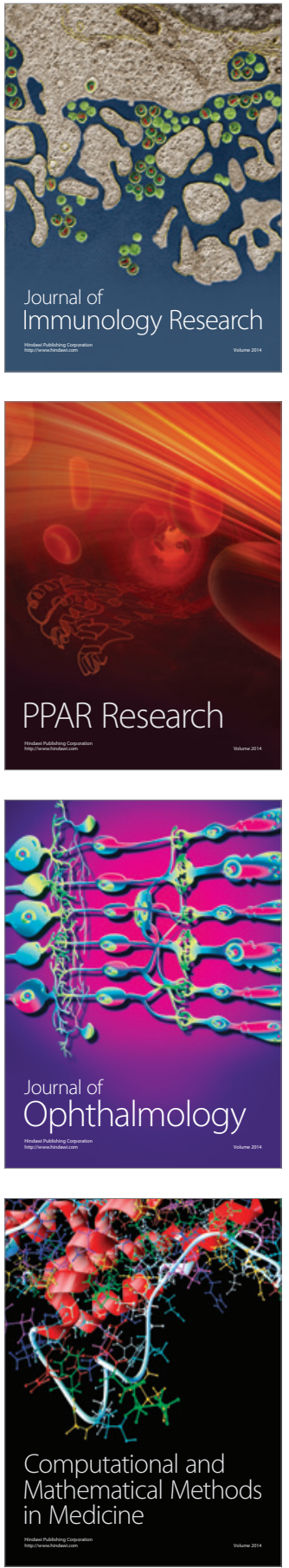

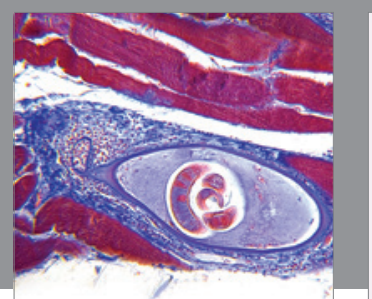

Gastroenterology Research and Practice

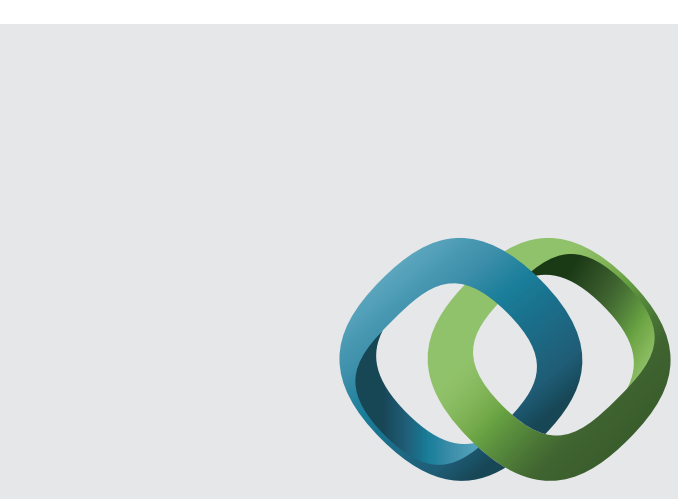

\section{Hindawi}

Submit your manuscripts at

http://www.hindawi.com
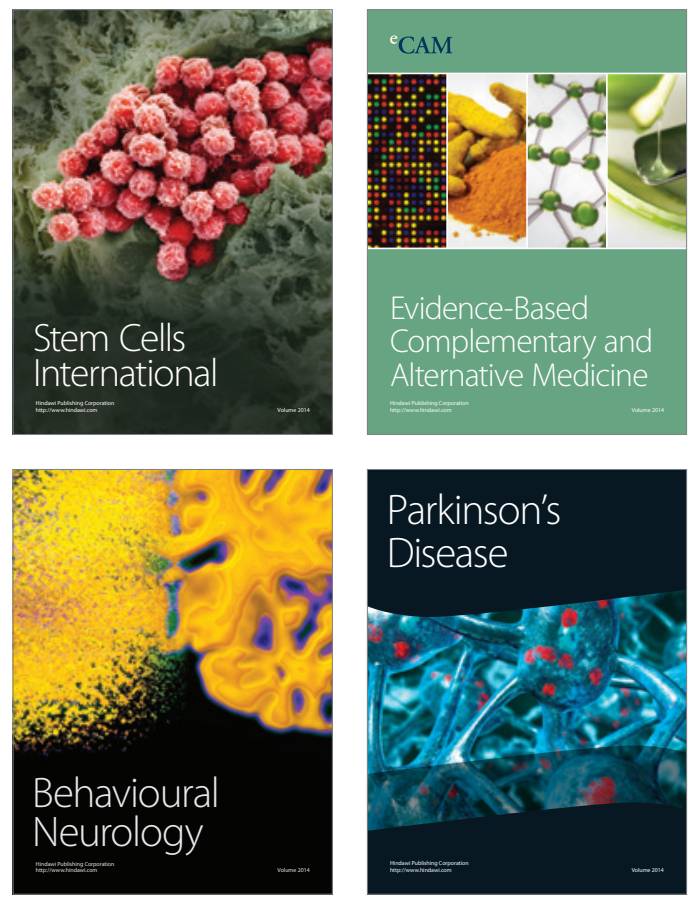
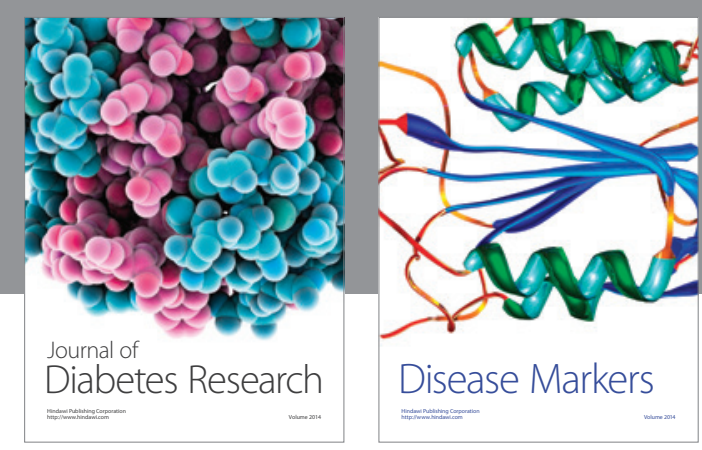

Disease Markers
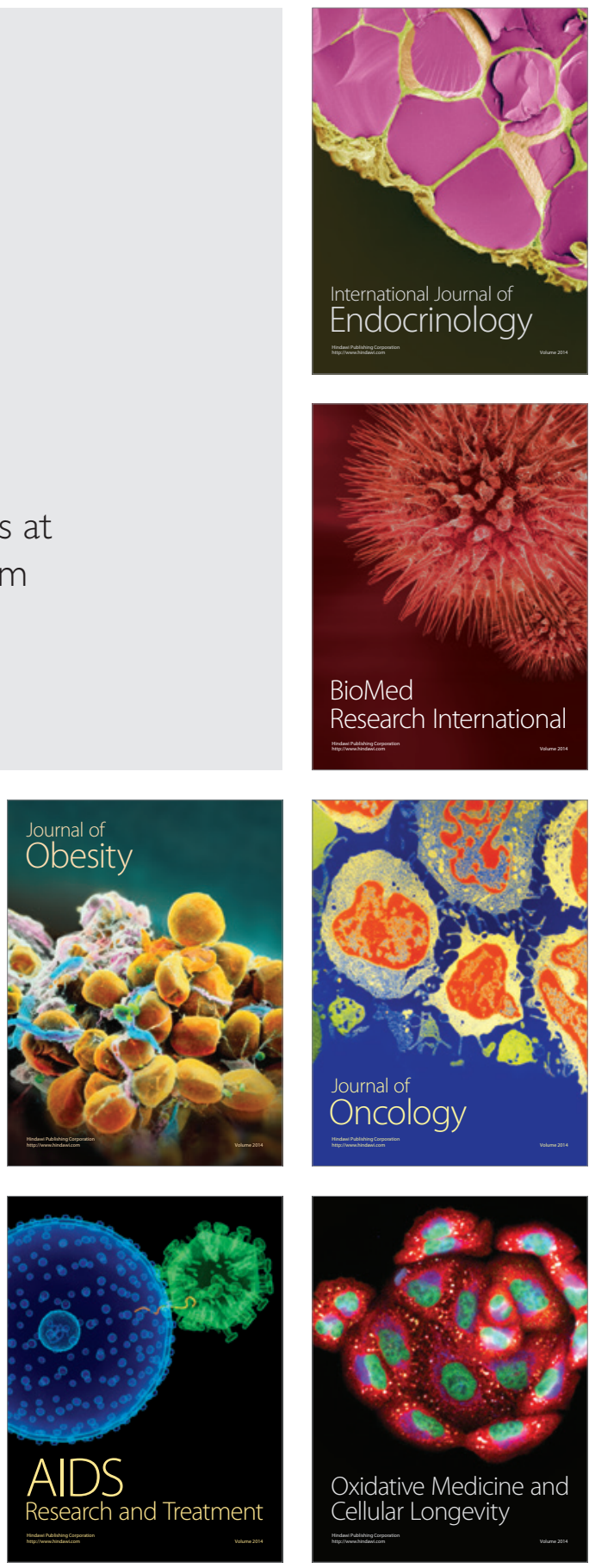